arrangement and application, and then to thrust it before a distrustful public, to solicit the attention and patronage of the gorernment for the proper attestation of its merits.

It was novel to the American people; no one had projected the thing here successfully, though many had thought of, and some tried it; through Professor Morse's indefatigable perseverance, the adjuvant resources of science were united in the form of utility; though dependant for most of his information upon others, he had the confidence in its final success, to master opposing obstacles, and bring to his aid, those who had lahored honorably and prosperously in the progress of knowledge.

To be continued.

For the Journal of the Franklin Institute.

\title{
On P. V. Du Trembley's Combined Vapor Engine.
}

At the works of Messrs Stillman \& Allen, New York, there is now in operation, one of Du 'Trembley's combined vapor engines, which is worthy of notice from its peculiar construction; but more particularly as it is claimed by the inventor, that 50 per cent. of the fuel used in the ordinary steam engine and boiler, will in the combined engine be saved; or, in other words, a given amount of fuel will do twice the work in the combined vapor cligine, that it will in the ordinary steam engine, a result most deviuily to be wished, no matter how cheap fuel may become. A description of the engine is here given in the inventor's own language:-

"This incention is applicd either to a single engine, with two cylinders and pistons, or, os is usual for maritine purposes, two distinct engines, with a cylinder and piston each. In either case, one of the pistons is acted upon by steam, and the other by the vapor of perchloride, or of any other exsily vaporized liquid, termed auxiliary liquid. 'The steam poser is generated and applied as in the ordinary enginc; but upon the escape of the steam from the first evlinter, after having exerted its expansive force therein, it passes inte an air-tight case, termed a vaporizer, containing a number of suall tubes charged with perchloride, or some casily vaporized liquid, penctrates into the space between, and comes in contact with the cutire surface of the tubes. . The faculty of absorbing caloric, possessed by liquids of the before mentioned cliss; is so powcrful, that immediately upon the steam coming in contact with the surface of the tubes charged therewith, a large portion of the caloric of the steam is absorbed by the liquid in the tubes, which becomes thereby vaporized, and the steam being thus deprived of its calorie, is immediately condensed and is then returned into the stean biniler. The vapor thus obtained by the action of the meam, or perchloride, or other liquid in the tubes, termed auxiliary vapor, is conducted into the sccond cylinder, and after exerting its clastic force (which is greater than steam) upon the piston in the second cylinder, is condensed, and by means of a force pump is returned into the vaporizer, which it thus keeps : regularly supplied, and is alternately vaporized and condensed. The saving effected by this engine is in the small quantity of coals required for the stcam, the smallor room occupied by it, and the avoidance of incrustation in the boiler, the water being completely distilled by the reiteration, vaporization, and condensation. The perchloride is a very cheap fluid; when once charged, the quantity in the tubes will last a considerable time, the alternate condensation and vaporization oceasioning a very trifling loss in the bulk or quantity employed. Every liquid boiling at - low temperature can be uscd. The best, according to the trials, are sulphuric ether, mulphur of carlon, chloroforn, chloride of carbon; the first two are inflammable, the last two are not."

Without discussing the practical merits of the invention, I should like enquire if the same economic result could not be produced by using easily raporized liquid directly in the boiler itself. Second, what W result (if ay) would be produced by the oil, which has occasionally 
to be used in every working cylinder. In long voyages, this oil in the aggregate, amounts to a large quantity, and some means are absolutely necessary to get rid of it. Will not the mixture of nil with the easily vaporized liquid change in some way its nature? I hope that Mr. Du 'Trembley has accomplished all he states, and that his engine will prove something more than a model.

Fulton.

For the Journal of the Franklin Institute.

Passage of the Steamer Baltic from Liverpool.

The Quickest Trip on Record, has been made by the steamer Baltic of the Collins line of steamers. She left Liverpool at 4 o'clock P. M., on Wednesday the 6th of August, and passed the battery at New York, at 20 minutes past 6 , on Saturday morning the 16 th. Apparent time 9 days, 14 hours, 20 minutes. Actual time 9 days, 18 hours, 45 minutes. She had good weather and fair winds for the greater part of the passage, and her daily run was as follows:-

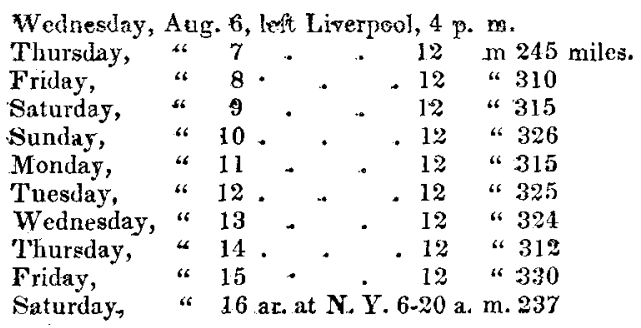

On the arrival of the Balice, the engineers of the Pacific presented to the engineers of the Baltic, the wreath of championship which they had received at the time they made their quick trip, it being well understood that the one who makes the quickest trip, is to have the custody of the said wreath, and is of course, by right, the champion of the line, to say nothing of the Cunard steamers, which are now allowed to arrive and lepart without note, so far as speed is concerned.

$\mathrm{H}$.

\section{For the Journal of the Franklin Institute.}

\section{Lake Steamer Buckeye State.}

This vessel, recently added to our lake fleet, has some peculiar features in her machinery, which render her worthy of special note. She has one of Smith \& Baird's compound expansion annular beam engines, being the first of the kind applied to any steamer in this or any country; the whole has been arranged by Erastus W. Smith, Esq., engineer, of New York City, and is a good specimen of engineering: The peculiar feature of this engine, is the employment of two cylinders, one being situated within the other, both having the same stroke of piston. 'The small cylinder has a diameter of 37 inehes, and a stroke of 11 feet, and into it the steam from the boiler of $40 \mathrm{lbs}$. average pressure is admitted, by a set of double balance valves, of the usual form. The larger cylinder surrounds the inner one, its diameter is 80 inches. The space between the two 